\title{
A cross-sectional study of self-reported general health, lifestyle factors, and disease: The Hordaland Health Study
}

Background: Information on self-reported health is important for health professionals, and the aim of this study was to examine associations between lifestyle factors and self-reported health and the mediating effect of disease in a Norwegian population. Methods and materials: The data collection was conducted as part of the Hordaland Health Study (HUSK) 1997-99, which was a cross-sectional epidemiological study. All individuals in Hordaland county born 1953-57 were invited to participate (aged 40-44 years). Complete information for the present study was obtained from 12,883 individuals (44\% response rate). Height and weight were measured at a physical examination. Information on lifestyle factors, selfreported health, disease (heart attack, apoplexy, angina pectoris, and diabetes), and sociodemographic variables was obtained from a self-administered questionnaire. Self-reported health was measured with a one-item question. Odds ratios for fair or poor self-reported health were calculated using multiple logistic regression analyses adjusted for disease and socio-demographic variables. Results: Respondents reporting adverse lifestyle behaviours (obesity (odds ratio (OR) 1.7, $p<0.001$ ), smoking (OR 1.2, $p<0.001$ ), or excessive intake of alcohol (OR 3.3, $p<0.001)$ ) showed an increased risk of poor self-reported health. Furthermore, a moderate intake of wine (OR $0.6, p<0.001)$ or strenuous physical activity (OR $0.5, p<0.001$ ) decreased the risk of poor health. Disease did not mediate the effect.

Conclusion: A one-item question measuring self-reported health may be a suitable measure for health professionals to identify levels of subjective health and reveal a need to target lifestyle factors in relatively young individuals with or without disease. 
1 Randi Jepsen ${ }^{1,2}$, Tadesse Washo Dogisso ${ }^{1}$, Elin Dysvik ${ }^{3}$, John Roger Andersen ${ }^{2,}{ }^{4}$, Gerd Karin 2 Natvig $^{1}$

$3{ }^{1}$ Department of Global Public Health and Primary Care, University of Bergen, Bergen, Norway

$4 \quad{ }^{2}$ Faculty of Health Studies, Sogn og Fjordane University College, Førde, Norway

$5{ }^{3}$ Department of Health Studies, University of Stavanger, Stavanger, Norway

$6 \quad{ }^{4}$ Førde Health Trust, Førde, Norway

7 E-mail:

8 Randi Jepsen: randi.jepsen@hisf.no

9 Tadesse Washo Dogisso: worba2008@yahoo.com

10 Elin Dysvik: elin.dysvik@uis.no

11 John Roger Andersen: john.andersen@hisf.no

12 Gerd Karin Natvig: gerd.natvig@igs.uib.no

13 Corresponding author:

14 Randi Jepsen (andi.jepsen@,hisf.no), Sogn og Fjordane University College, Faculty of Health

15 Studies, Box 523, NO 6803 Førde, Norway, Telephone: +47 57722577, Fax: +47 57722501 


\section{Background}

17 Patient-reported information has been acknowledged over the past decades as measures to

18 capture subjective perspectives and inform and improve clinical practice. One of these measures

19 is self-reported health (Ahmed et al., 2012). Jylha has proposed a conceptual model to help

20 identifying the different types of information on which people base their health assessments. In

21 this model, the evaluation of one's own health encompasses a review of information, such as

22 functional status, diseases, health-related behaviours, and socio-demographic factors.

23 Additionally, the model consists of factors comprising contextual frameworks, such as cultural

24 conventions (Jylha, 2009). As an example of the significance of self-reported health, Idler and

25 Benyamini reported that it predicted mortality in almost all of the 27 community studies they

26 included in their review, and this connection may be seen as well established (Idler \& Benyamini,

27 1997). However, the question of how people may understand and interpret the concept of self-

28 reported health is not fully unravelled empirically.

29 Lifestyle factors are among the behaviours that individuals consider when they report

30 their own general health (Manderbacka, 1998; Jylha, 2009) and previous research found that

31 cigarette smoking and alcohol consumption were related to reduced physical and mental health

32 (Riise, Moen \& Nortvedt, 2003). In addition, obesity has been found as a predictor of self-rated

33 health (Prosper, Moczulski \& Qureshi, 2009). The experience of general health has also been

34 found to be positively associated with levels of physical activity (Malmberg et al., 2005). One

35 study, including several lifestyle factors, found a negative relationship between unhealthy

36 lifestyle and mental and physical health (Pisinger et al., 2009). Another study (Manderbacka,

37 Lundberg \& Martikainen, 1999) examined whether different risk factors contributed to self-

38 reported health, when the effect of various health problems were also included. In this study, the 
39 authors examined the relationship between risk factors, such as dietary habits, exercise, smoking,

40 alcohol consumption, and body mass index (BMI), and self-reported health. The authors found

41 that these associations were weakened or not significant at all when they were adjusted for health

42 problems. However, these health problem variables were composed by, on the one hand,

43 subjective phenomena including symptoms and functional problems, which may overlap the

44 concept of self-reported health, and, on the other hand, objective medical diagnoses. Thus, the

45 specific significance of the diseases was not revealed. Therefore, the aim of the present study was

46 to examine associations between various lifestyle factors and self-reported health and the

47 mediating effect of disease. The research question guiding the study was if lifestyle factors

48 (smoking, alcohol consumption, leisure time physical activity, and BMI) worked as risk factors

49 for self-reported general health in an adult Norwegian population, with adjustment for socio-

50 demographic characteristics (gender, marital status, and educational level) and diseases (coronary

51 heart disease, apoplexy, and diabetes).

\section{Methods and materials}

\section{Design and sample}

54 The Hordaland Health Study (HUSK) was conducted during 1997-99 as a collaboration between

55 the National Health Screening Service, the University of Bergen, and local health services. The

56 study design was cross-sectional. The study population included all individuals in Hordaland

57 county born 1953-57 (29,400). A total of 8,584 men and 9,976 women participated, yielding a

58 participation rate of $57 \%$ for men and $70 \%$ for women. Complete information of all variables

59 included in the present study was available for 12,883 individuals ( $44 \%$ of the study population). 


\section{PeerJ Reviewing Manuscript}

\section{Ethical approval}

61 Written informed consent was obtained from each participant prior to the study. The study

62 protocol was approved by the Regional Committee for Medical Research Ethics, Health Region

63 III (reference number 311/97-64.97) and the Norwegian Data Inspectorate (reference number

64 97/1504-2). The study conforms to the Declaration of Helsinki.

\section{Measures}

66 Information on self-rated health, lifestyle factors, diseases, and socio-demographic variables were

67 obtained from a self-administered questionnaire which was sent by mail together with a letter of

68 invitation and the time of appointment for a physical examination. The questionnaire was

69 collected and height and weight were measured at the examination (Naess et al., 2008).

70 Self-rated health was measured by one question: "How is your health at the moment?"

71 with four response categories: “poor", "fair", "good”, and "very good”.In their review of

72 community studies, Idler and Benyami (1997) found that one-item measures on self-reported

73 health revealed significant, independent associations with mortality. The Norwegian measure

74 used in this study has previously shown predictive value for morbidity (Naess et al., 2005; Riise

75 et al., 2014) and mortality (Dalen et al., 2012).

76 The measures of lifestyle were leisure time physical activity, tobacco smoking, alcohol

77 consumption, and BMI. Physical activity was assessed by the Cohort of Norway (CONOR)

78 instrument which comprises two questions about the average weekly number of hours of either

79 light (not sweaty or short of breath) or strenuous leisure time physical activity the last year

80 (Graff-Iversen et al., 2008). The categories are "none", "less than 1 hour", "1-2 hours", or "3

81 hours or more" for both questions. Validity of this CONOR instrument has been demonstrated

82 through correlation with anthropometric and biological variables in epidemiological research

83 (Aires, Selmer \& Thelle, 2003; Graff-Iversen et al., 2008). Data on tobacco use were obtained 
84 from questions about current and former smoking habits. This measure has shown predictive

85 validity for the risk of coronary heart disease (Igland et al., 2012). Alcohol concumption was

86 measured with items about the prevalence of consumption of wine, beer, and liquor within the

87 last two weeks. This instrument has shown predictive validity in epidemiological research

88 (Torvik, Rognmo \& Tambs, 2012).

89 BMI was calculated as kilograms per square meter and categorised in accordance with the

90 World Health Organization classification of underweight $\left({ }^{<} 18.5 \mathrm{~kg} / \mathrm{m}^{2}\right)$, normal weight (18.5-

91 24.9), overweight (25-29.9), obesity grade I (30-34.9), and obesity grade II and more (35+)

92 (World Health Organization, 1998).

\section{Statistical analyses}

94 The responses on self-reported health were dichotomized into "very good/good" and "fair/poor".

95 Marital status was dichotomized into "married/cohabiting" or "other". Education was used as an

96 indicator of socioeconomic status and the five categories for educational level were coded as

97 "low" (up to and including 10 years of schooling), "medium" (high school), and "high"

98 (college/university). A dichotomous variable of "not having a disease" or "having one or more

99 diseases" was coded from self-reported occurence of heart attack, apoplexy, angina pectoris, and

100 diabetes. Data on tobacco smoking were coded into three categories; "never a smoker", "formerly

101 a smoker" (without specification of time since cessation), or "currently a smoker". Units of

102 alcohol per two weeks were catogorized as "none", "1-14", or " 15 or more" for wine, beer, and

103 liquor, respectively. 15 units/two weeks have previously been used as a cut-off point for high

104 alcohol consumption (Myrtveit et al., 2013).

105 Descriptive statistics were used to present the sample. Univariate and multivariate logistic

106 regression were applied to study associations between lifestyle factors (consumption of wine,

107 beer, and liquor; light and strenuous physical activity; smoking; and BMI) and self-rated health. 
108 Disease, gender, marital status, and educational level were included as covariates. The age range

109 was very small, and preliminary analysis showed that it did not influence the results (data not

110 shown). Therefore, it was not included in the analysis. A $p$-value $\leq 0.05$ indicated statistical

111 significance. The statistical package IBM SPSS for Windows, version 20.0, was used in the 112 analyses.

\section{Results}

\section{Study sample}

115 All study participants $(12,883)$ were aged $40-44$ years. Among these, $51.4 \%$ were women (Table

116 1). A smaller proportion (11.5\%) had a BMI of 30 or more, i.e., obesity, while $49.5 \%$ were of

117 normal weight. The most excessive alcohol consumption was reported by $1 \%$ of the participants

118 for wine, $2.2 \%$ for beer and $0.2 \%$ for liquor. Fourty-three percent reported doing light physical

119 activity and $13.1 \%$ strenuous physical activity for three hours or more per week. Current smoking

120 was reported by $34.4 \%$ of the participants. Currently having or having experienced coronary heart

121 disease, apoplexy, and/or diabetes were reported by $9.8 \%$ (Table 1 ).

122 Female gender and not being married/cohabiting were related to higher odds for fair or

123 poor health. Favourable self-reported health increased with level of education (Table 2).

\section{Lifestyle factors and self-rated health}

125 As seen in Table 1, 87\% of the participants rated their health as very good or good, and $13 \%$ as

126 fair or poor. In Table 2, the odds of rating health as fair or poor are shown. Among the lifestyle-

127 related variables, obesity was significantly related to an increased risk of fair or poor health.

128 Being a current smoker also increased the odds ratio of fair or poor health whereas the unadjusted

129 analysis - but not the adjusted - revealed better health in former smokers than in participants who

130 never smoked. In addition, the consumption of 15 or more units of liquor per two weeks was 
131 significantly related to adverse self-reported health. On the other hand, a moderate intake of wine

132 or beer (1-14 units per two weeks) decreased the odds ratio of fair or poor health. The same

133 applied to both light and strenuous physical activity. The associations between self-reported

134 health and lifestyle factors were similar, whether socio-demographic variables or the disease

135 variable were included into the statistical model or not. Hence, we did not find a mediating effect

136 of the disease variable.

\section{Discussion}

138 In this population study we found that the risk of adverse self-reported health was related to

139 obesity, current smoking, and consumption of 15 or more units of liquor per two weeks. On the

140 other hand, a moderate intake of wine or beer and leisure time physical activity decreased the risk

141 of unfavourable self-reported health.

142 Self-reported health, as measured by a one-item scale, has previously been well

143 established as a predictor of mortality (Idler \& Benyamini, 1997; Dalen et al., 2012) and previous

144 studies also found that self-reported health was a predictor of diabetes (Naess et al., 2005) and

145 lung cancer (Riise et al., 2014). The question of what kind of information each individual bases

146 his or her evaluation on when answering this question, is previously discussed and encompasses a

147 wide range of factors of both individual and contextual character. Among these factors are

148 lifestyle behaviours (Manderbacka, 1998; Jylha, 2009).

149 Overweight and obesity have a broad spectrum of individual, social, and environmental

150 explanatory factors, and can also be seen as lifestyle-related health problems (World Health

151 Organization, 1998). Furthermore, it is a rising public health and clinical problem (Fruhbeck et

152 al., 2013) and data from the Norwegian population show that the levels of body weight have

153 increased during the recent decades (Midthjell et al., 2013). The prevalence of overweight among 
154 children and adolescents is high too (Dupuy et al., 2011). As in the present study, Prosper and

155 colleagues found that high levels of BMI were predictors of adverse self-reported health (Prosper,

156 Moczulski \& Qureshi, 2009). Similar findings are reported with health-related quality of life

157 (Soltoft, Hammer \& Kragh, 2009). Previous research has also shown that high levels of BMI are

158 associated with cardiovascular risk (Jonsson et al., 2002) and mortality (Flegal et al., 2013).

159 One of the main changes in health behaviours in the past years has been a decrease in

160 physical activity both at work and at leisure, and the rise in overweight and obesity is often

161 connected to this problem (Anderssen et al., 2008). One recent study found that obese participants

162 had lower overall physical activity compared to normal weight participants (Hansen et al., 2013).

163 Physical activity can also be positively associated with self-reported health, irrespective of an

164 increased BMI (Herman et al., 2012). We found that both light and strenuous physical activity

165 decreased the risk of fair or poor health. A similar finding is reported previously (Tran et al.,

166 2013), and daily walking has been found to be inversely related to mortality among elderly

167 people (Samawi, 2013).

168 We found that the consumption of 15 or more units of liquor per two weeks increased the

169 odds ratio of fair or poor self-reported health, and this result is in accordance with previous

170 research on binge drinking (Tsai et al., 2010). The results regarding a decreased risk of adverse

171 health for individuals with a moderate intake of wine or beer, are more inconsistent. In examining

172 the association between harmful patterns of alcohol consumption and self-reported health status

173 measured by Euro-QoL Group's five-dimension questionnaire (EQ5D), Petrie et al. (2008) found

174 that all levels of risky alcohol use, including the low risk level, were associated with lower self-

175 ratings of health. There was, however, a small effect for those with a moderate alcohol intake. On

176 the other hand, previous studies, examining the association between moderate intake of alcohol

177 and diseases, found that a moderate intake of alcohol, including red wine, reduced the risk of

178 cardiovascular, cerebrovascular, and peripheral vascular diseases in populations (Szmitko \& 
179 Verma, 2005), and one recent study confirmed these results, showing that moderate alcohol

180 consumption was associated with lower risk of stroke in a population of women (Jimenez et al.,

181 2012). Furthermore, our result, showing that smoking was associated with poor health, is

182 supporting previous studies regarding self-reported health (Goldman, Glei \& Chang, 2004; Tran

183 et al., 2013) as well as health-related quality of life (Strine et al., 2008). Although the odds ratio

184 was small, it was unexpected that the unadjusted analysis revealed better health in former

185 smokers than in study participants who never smoked. Assocations between smoking cessation

186 and positive affect (Branstrom et al., 2010) or mental health (Taylor et al., 2014) may serve as an

187 explanation. However, Manderbacka, Lundberg \& Martikainen (1999) and Kaleta et al. (2006)

188 reported opposite results whereas Ho et al. (2003) found no statistical difference in self-rated

189 health between former and never smokers. None of the studies, including the present, took time

190 since smoking cessation into consideration.

191 Our finding that the disease variable did not mediate the effect of lifestyle factors on self-

192 reported health differs from the results reported by Manderbacka, Lundberg \& Martikainen

193 (1999). However, as mentioned, they included not only medical diagnoses, but also a range of

194 illnesses, functional problems, and symptoms in their operationalisation of health problems,

195 leaving the question of the role of diseases unanswered.

196 In line with other studies (Eriksson, Unden \& Elofsson, 2001; Nielsen et al., 2008), we

197 found that female gender was associated with fair or poor health. The same counted for living

198 alone. Joung et al. (1995) found that married men and women reported better health than

199 unmarried, partly independent of lifestyle factors. Helweg-Larsen, Kjøller \& Thoning (2003)

200 found higher mortality in unmarried than married individuals. The positive association between

201 length of education and self-rated health found in the present study was also reported by

202 Mackenbach et al. (2008) and Liu \& Hummer (2008). 
204 findings. Except for type 1 diabetes (Tao et al., 2010), the incidence of the medical conditions

205 included in the disease variable of our study increases with age (World Health Organization,

206 2011). The impact of disease on self-rated health may vary between age groups. There was no

207 information about the severity of the diseases we included in the disease variable, which may

208 have influenced the results of our study.

209 The data collection was performed in 1997-99. Hence, the study provides knowledge from

210 a time when one third of Norwegian adults were daily smokers, compared to the current situation

211 where less than one in five smokes tobacco on a daily basis (Norwegian Institute of Public

212 Health, 2014b), purchase of alcohol was lower (Norwegian Institute of Public Health, 2014a),

213 physical activity levels were higher (Anderssen et al., 2008), and the proportion of individuals

214 with overweight and obesity was at a rise (Midthjell et al., 2013). Changed patterns of lifestyle

215 may affect cultural conventions which, according to Jylha (Jylha, 2009), play a role in subjective

216 assessments of health.

\section{Methodological considerations}

218 The data material from HUSK is based on a large sample which gave statisitcal power to include

219 a number of variables in the multivariate analysis. Similar to other epidemiological surveys

220 (Sogaard et al., 2004), the response rate was rather low (44\%). Whether this created bias in the

221 results is not possible to determine. However, some studies indicate that non-participation may

222 not impact very much on associations between study variables in large health surveys (Søgaard et

223 al., 2004; Laaksonen et al., 2008). The data on height and weight were measured by clinicians

224 whereby we avoided the under-reporting for weight and over-reporting for height that are

225 common in self-reports (Connor Gorber et al., 2007). Due to the cross-sectional design of the

226 study we cannot infer causal relationships. 


\section{Conclusion}

228 A wide variety of factors are included when individuals are reporting how they evaluate their

229 current health. Our study adds to the body of empirical knowledge, showing associations between

230 unhealthy lifestyle and self-reported health which are not mediated by diseases in adults aged 40-

23144 years. As a supplement or alternative to health assessments and interpretations done by health

232 professionals, the one-item question may be suitable for health professionals as an instrument to

233 identify how patients or other recipients of health services evaluate their health and an indicator

234 of when lifestyle should be targeted in relatively young individuals with or without disease.

\section{Acknowledgements}

236 The authors would like to thank the HUSK study for the access to the data material. Gratitude is

237 extended to Ulla Borch Thomsen for her help with the English language. 


\section{References}

239

240

241

242

243

244

245

246

247

248

249

250

251

252

253

254

255

256

257

258

259

260

261

262

263

264

265

266

267

268

269

270

271

272

273

274

275

276

277

278

279

280

281

282

283

Ahmed S, Berzon RA, Revicki DA, Lenderking WR, Moinpour CM, Basch E, Reeve BB, Wu AW, International Society for Quality of Life Research. 2012. The use of patient-reported outcomes (PRO) within comparative effectiveness research: implications for clinical practice and health care policy. Medical Care 50:1060-1070.

Aires N, Selmer R, Thelle D. 2003. The validity of self-reported leisure time physical activity, and its relationship to serum cholesterol, blood pressure and body mass index. A population based study of 332,182 men and women aged 40-42 years. European Journal of Epidemiology 18:479-485.

Anderssen SA, Engeland A, Sogaard AJ, Nystad W, Graff-Iversen S, Holme I. 2008. Changes in physical activity behavior and the development of body mass index during the last 30 years in Norway. Scandinavian Journal of Medicine and Science in Sports 18:309-317.

Branstrom R, Penilla C, Perez-Stable EJ, Munoz RF. 2010. Positive affect and mood management in successful smoking cessation. American Journal of Health Behavior 34:553-562.

Connor Gorber S, Tremblay M, Moher D, Gorber B. 2007. A comparison of direct vs. self-report measures for assessing height, weight and body mass index: a systematic review. Obesity Reviews 8:307-326.

Dalen JD, Huijts T, Krokstad S, Eikemo TA. 2012. Are there educational differences in the association between self-rated health and mortality in Norway? The HUNT Study. Scandinavian Journal of Public Health 40:641-647.

Dupuy M, Godeau E, Vignes C, Ahluwalia N. 2011. Socio-demographic and lifestyle factors associated with overweight in a representative sample of 11-15 year olds in France: results from the WHO-Collaborative Health Behaviour in School-aged Children (HBSC) cross-sectional study. BMC Public Health 11:442.

Eriksson I, Unden AL, Elofsson S. 2001. Self-rated health. Comparisons between three different measures. Results from a population study. International Journal of Epidemiology 30:326-333.

Flegal KM, Kit BK, Orpana H, Graubard BI. 2013. Association of all-cause mortality with overweight and obesity using standard body mass index categories: a systematic review and meta-analysis. JAMA 309:71-82.

Fruhbeck G, Toplak H, Woodward E, Yumuk V, Maislos M, Oppert JM, Executive Committee of the European Association for the Study of Obesity. 2013. Obesity: the gateway to ill health - an EASO position statement on a rising public health, clinical and scientific challenge in Europe. Obesity Facts 6:117-120.

Goldman N, Glei DA, Chang MC. 2004. The role of clinical risk factors in understanding selfrated health. Annals of Epidemiology 14:49-57.

Graff-Iversen S, Anderssen SA, Holme IM, Jenum AK, Raastad T. 2008. Two short questionnaires on leisure-time physical activity compared with serum lipids, anthropometric measurements and aerobic power in a suburban population from Oslo, Norway. European Journal of Epidemiology 23:167-174.

Hansen BH, Holme I, Anderssen SA, Kolle E. 2013. Patterns of objectively measured physical activity in normal weight, overweight, and obese individuals (20-85 years): a crosssectional study. PloS One 8:e53044.

Helweg-Larsen M, Kjøller M, Thoning H. 2003. Do age and social relations moderate the relationship between self-rated health and mortality among adult Danes? Social Science and Medicine 57:1237-1247.

PeerJ reviewing PDF | (v2014:05:2127:1:0:NEW 9 Sep 2014) 
284

285

286

287

288

289

290

291

292

293

294

295

296

297

298

299

300

301

302

303

304

305

306

307

308

309

310

311

312

313

314

315

316

317

318

319

320

321

322

323

324

325

326

327

328

329

330

Herman KM, Hopman WM, Vandenkerkhof EG, Rosenberg MW. 2012. Physical activity, body mass index, and health-related quality of life in Canadian adults. Medicine and Science in Sports and Exercise 44:625-636.

Ho SY, Lam TH, Fielding R, Janus ED. 2003. Smoking and perceived health in Hong Kong Chinese. Social Science and Medicine 57:1761-1770.

Idler EL, Benyamini Y. 1997. Self-rated health and mortality: a review of twenty-seven community studies. Journal of Health and Social Behavior 38:21-37.

Igland J, Vollset SE, Nygard OK, Gjessing HK, Ueland PM, Tell GS. 2012. Relative importance of risk factors for coronary heart disease--the Hordaland Homocysteine study. Scandinavian Cardiovascular Journal 46:316-323.

Joung IM, Stronks K, van de Mheen H, Mackenbach JP. 1995. Health behaviours explain part of the differences in self reported health associated with partner/marital status in The Netherlands. Journal of Epidemiology and Community Health 49:482-488.

Jylha M. 2009. What is self-rated health and why does it predict mortality? Towards a unified conceptual model. Social Science and Medicine 69:307-316.

Jimenez M, Chiuve SE, Glynn RJ, Stampfer MJ, Camargo CA, Jr., Willett WC, Manson JE, Rexrode KM. 2012. Alcohol consumption and risk of stroke in women. Stroke 43:939945.

Jonsson S, Hedblad B, Engstrom G, Nilsson P, Berglund G, Janzon L. 2002. Influence of obesity on cardiovascular risk. Twenty-three-year follow-up of 22,025 men from an urban Swedish population. International Journal of Obesity and Related Metabolic Disorders 26:1046-1053.

Kaleta D, Makowiec-Dabrowska T, Dziankowska-Zaborszczyk E, Jegier A. 2006. Physical activity and self-perceived health status. International Journal of Occupational Medicine and Environmental Health 19:61-69.

Laaksonen M, Aittomaki A, Lallukka T, Rahkonen O, Saastamoinen P, Silventoinen K, Lahelma E. 2008. Register-based study among employees showed small nonparticipation bias in health surveys and check-ups. Journal of Clinical Epidemiology 61:900-906.

Liu H, Hummer RA. 2008. Are educational differences in U.S. self-rated health increasing?: an examination by gender and race. Social Science and Medicine 67:1898-1906.

Mackenbach JP, Stirbu I, Roskam AJ, Schaap MM, Menvielle G, Leinsalu M, Kunst AE, European Union Working Group on Socioeconomic Inequalities in Health. 2008. Socioeconomic inequalities in health in 22 European countries. New England Journal of Medicine 358:2468-2481.

Malmberg J, Miilunpalo S, Pasanen M, Vuori I, Oja P. 2005. Characteristics of leisure time physical activity associated with risk of decline in perceived health--a 10-year follow-up of middle-aged and elderly men and women. Preventive Medicine 41:141-150.

Manderbacka K. 1998. Examining what self-rated health question is understood to mean by respondents. Scandinavian Journal of Social Medicine 26:145-153.

Manderbacka K, Lundberg O, Martikainen P. 1999. Do risk factors and health behaviours contribute to self-ratings of health? Social Science and Medicine 48:1713-1720.

Midthjell K, Lee CM, Langhammer A, Krokstad S, Holmen TL, Hveem K, Colagiuri S, Holmen J. 2013. Trends in overweight and obesity over 22 years in a large adult population: the HUNT Study, Norway. Clinical Obesity 3:12-20.

Myrtveit SM, Ariansen AM, Wilhelmsen I, Krokstad S, Mykletun A. 2013. A population based validation study of self-reported pensions and benefits: the Nord-Trøndelag health study (HUNT). BMC Research Notes 6:27.

PeerJ reviewing PDF | (v2014:05:2127:1:0:NEW 9 Sep 2014) 
331

332

333

334

335

336

337

338

339

340

341

342

343

344

345

346

347

348

349

350

351

352

353

354

355

356

357

358

359

360

361

362

363

364

365

366

367

368

369

370

371

372

373

374

375

376

377

Naess O, Sogaard AJ, Arnesen E, Beckstrom AC, Bjertness E, Engeland A, Hjort PF, Holmen J, Magnus P, Njolstad I, Tell GS, Vatten L, Vollset SE, Aamodt G. 2008. Cohort profile: cohort of Norway (CONOR). International Journal of Epidemiology 37:481-485.

Naess S, Eriksen J, Midthjell K, Tambs K, Nord-Trøndelag Health Study. 2005. Subjective wellbeing before and after the onset of diabetes mellitus: results of the Nord-Trøndelag Health Study. Journal of Diabetes and Its Complications 19:88-95.

Nielsen AB, Siersma V, Hiort LC, Drivsholm T, Kreiner S, Hollnagel H. 2008. Self-rated general health among 40-year-old Danes and its association with all-cause mortality at 10-, 20-, and 29 years' follow-up. Scandinavian Journal of Public Health 36:3-11.

Norwegian Institute of Public Health. 2014a. Alcohol consumption in Norway - fact sheet. Available at http://www.fhi.no/artikler/?id=86717 (accessed 22 March 2014).

Norwegian Institute of Public Health. 2014b. Smoking and smokeless tobacco in Norway - fact sheet. Available at http://www.fhi.no/artikler/?id=84434 (accessed 22 March 2014).

Petrie D, Doran C, Shakeshaft A, Sanson-Fisher R. 2008. The relationship between alcohol consumption and self-reported health status using the EQ5D: evidence from rural Australia. Social Science and Medicine 67:1717-1726.

Pisinger C, Toft U, Aadahl M, Glumer C, Jorgensen T. 2009. The relationship between lifestyle and self-reported health in a general population: the Inter99 study. Preventive Medicine 49:418-423.

Prosper MH, Moczulski VL, Qureshi A. 2009. Obesity as a predictor of self-rated health. American Journal of Health Behavior 33:319-329.

Riise HK, Riise T, Natvig GK, Daltveit AK. 2014. Poor self-rated health associated with an increased risk of subsequent development of lung cancer. Quality of Life Research 23:145-153.

Riise T, Moen BE, Nortvedt MW. 2003. Occupation, lifestyle factors and health-related quality of life: the Hordaland Health Study. Journal of Occupational and Environmental Medicine 45:324-332.

Samawi HM. 2013. Daily walking and life expectancy of elderly people in the iowa $65+$ rural health study. Frontiers in Public Health 1:11.

Soltoft F, Hammer M, Kragh N. 2009. The association of body mass index and health-related quality of life in the general population: data from the 2003 Health Survey of England. Quality of Life Research 18:1293-1299.

Strine TW, Chapman DP, Balluz LS, Moriarty DG, Mokdad AH. 2008. The associations between life satisfaction and health-related quality of life, chronic illness, and health behaviors among U.S. community-dwelling adults. Journal of Community Health 33:40-50.

Szmitko PE, Verma S. 2005. Antiatherogenic potential of red wine: clinician update. American Journal of Physiology: Heart and Circulatory Physiology 288:H2023-2030.

Sogaard AJ, Selmer R, Bjertness E, Thelle D. 2004. The Oslo Health Study: The impact of selfselection in a large, population-based survey. International Journal for Equity in Health $3: 3$.

Tao B, Pietropaolo M, Atkinson M, Schatz D, Taylor D. 2010. Estimating the cost of type 1 diabetes in the U.S.: a propensity score matching method. PloS One 5:e11501.

Taylor G, McNeill A, Girling A, Farley A, Lindson-Hawley N, Aveyard P. 2014. Change in mental health after smoking cessation: systematic review and meta-analysis. $B M J$ 348:g1151.Torvik FA, Rognmo K, Tambs K. 2012. Alcohol use and mental distress as predictors of non-response in a general population health survey: the HUNT study. Social Psychiatry and Psychiatric Epidemiology 47:805-816.

PeerJ reviewing PDF | (v2014:05:2127:1:0:NEW 9 Sep 2014) 
378 Tran TV, Nguyen D, Chan K, Nguyen TN. 2013. The association of self-rated health and lifestyle 379 behaviors among foreign-born Chinese, Korean, and Vietnamese Americans. Quality of $380 \quad$ Life Research 22:243-252.

381 Tsai J, Ford ES, Li C, Pearson WS, Zhao G. 2010. Binge drinking and suboptimal self-rated 382

383 1471.

World Health Organization. 1998. Obesity: preventing and managing the global epidemic. Report of a WHO consultation. WHO technical report series. Geneva: World Health Organization.

World Health Organization. 2011. Global status report on noncommunicable diseases 2010. 


\section{Table 1 (on next page)}

Characteristics of the participants $(N=12,883)$ 
PeerJ Reviewing Manuscript

\begin{tabular}{|c|c|}
\hline Variables & $\%$ \\
\hline \multicolumn{2}{|l|}{ Self-rated health } \\
\hline Very good/good & 87.0 \\
\hline Fair/poor & 13.0 \\
\hline \multicolumn{2}{|l|}{ Gender } \\
\hline Male & 48.6 \\
\hline Female & 51.4 \\
\hline \multicolumn{2}{|l|}{ Marital status } \\
\hline Married/cohabiting & 74.6 \\
\hline Other & 25.4 \\
\hline \multicolumn{2}{|l|}{ Education } \\
\hline Low & 17.0 \\
\hline Medium & 45.8 \\
\hline High & 37.2 \\
\hline \multicolumn{2}{|c|}{ Disease (coronary heart disease, apoplexy, or diabetes) } \\
\hline No & 90.2 \\
\hline Yes & 9.8 \\
\hline \multicolumn{2}{|l|}{ Body mass index } \\
\hline$<18.5$ & 0.8 \\
\hline $18.5-24.9$ & 49.5 \\
\hline $25-29.9$ & 38.8 \\
\hline $30-34.9$ & 9.1 \\
\hline $35+$ & 2.4 \\
\hline \multicolumn{2}{|c|}{ Wine (units per two weeks) } \\
\hline None & 50.7 \\
\hline $1-14$ & 48.3 \\
\hline $15+$ & 1.0 \\
\hline \multicolumn{2}{|c|}{ Beer (units per two weeks) } \\
\hline None & 54.2 \\
\hline $1-14$ & 43.6 \\
\hline $15+$ & 2.2 \\
\hline \multicolumn{2}{|c|}{ Liquor (units per two weeks) } \\
\hline None & 79.1 \\
\hline $1-14$ & 20.8 \\
\hline $15+$ & 0.2 \\
\hline \multicolumn{2}{|c|}{ Light physical activity (hours per week) } \\
\hline None & 4.3 \\
\hline$<1$ & 14.6 \\
\hline $1-2$ & 38.1 \\
\hline $3+$ & 43.0 \\
\hline \multicolumn{2}{|c|}{ Strenuous physical activity (hours per week) } \\
\hline None & 29.7 \\
\hline$<1$ & 28.8 \\
\hline $1-2$ & 28.4 \\
\hline $3+$ & 13.1 \\
\hline \multicolumn{2}{|l|}{ Smoking } \\
\hline Never smoker & 37.6 \\
\hline Former smoker & 28.0 \\
\hline Current smoker & 34.4 \\
\hline
\end{tabular}




\section{Table 2 (on next page)}

Odds ratio (OR) with 95\% confidence intervals $(\mathrm{Cl})$ for fair or poor self-rated health $(N=$ 12,883) 


\begin{tabular}{|c|c|c|c|c|c|c|}
\hline \multirow[b]{2}{*}{ Variables } & \multirow[b]{2}{*}{ OR } & \multicolumn{2}{|c|}{ Univariate model } & \multicolumn{3}{|c|}{ Multivariate model } \\
\hline & & $95 \% \mathrm{CI}$ & $p$-value & OR & $95 \% \mathrm{CI}$ & $p$-value \\
\hline \multicolumn{7}{|l|}{ Gender } \\
\hline Male (ref) & 1 & & & 1 & & \\
\hline Female & 1.4 & $1.2,1.5$ & $<0.001$ & 1.3 & $1.2,1.5$ & $<0.001$ \\
\hline \multicolumn{7}{|l|}{ Marital status } \\
\hline Married/cohabiting (ref) & 1 & & & 1 & & \\
\hline Other & 1.5 & $1.4,1.8$ & $<0.001$ & 1.5 & $1.4,1.7$ & $<0.001$ \\
\hline \multicolumn{7}{|l|}{ Education } \\
\hline Low (ref) & 1 & & & 1 & & \\
\hline Medium & 0.6 & $0.5,0.7$ & $<0.001$ & 0.7 & $0.6,0.8$ & $<0.001$ \\
\hline High & 0.4 & $0.4,0.5$ & $<0.001$ & 0.6 & $0.5,0.7$ & $<0.001$ \\
\hline \multicolumn{7}{|l|}{ Disease } \\
\hline No (ref) & 1 & & & 1 & & \\
\hline $1+$ & 2.9 & $2.5,3.3$ & $<0.001$ & 2.7 & $2.3,3.1$ & $<0.001$ \\
\hline \multicolumn{7}{|l|}{ Body mass index } \\
\hline$<18.5$ & 1.5 & $0.9,2.5$ & 0.149 & 1.2 & $0.7,2.0$ & 0.556 \\
\hline $18.5-24.9$ (ref) & 1 & & & 1 & & \\
\hline $25-29.9$ & 1.1 & $0.9,1.1$ & 0.422 & 1.1 & $1.0,1.3$ & 0.089 \\
\hline $30-34.9$ & 1.9 & $1.6,2,1$ & $<0.001$ & 1.6 & $1.3,1.9$ & $<0.001$ \\
\hline $35+$ & 2.3 & $1,8,3.1$ & $<0.001$ & 1.7 & $1.3,2.3$ & $<0.001$ \\
\hline \multicolumn{7}{|l|}{ Wine (units per two weeks) } \\
\hline None (ref) & 1 & & & 1 & & \\
\hline $1-14$ & 0.5 & $0.5,0.6$ & $<0.001$ & 0.7 & $0.6,0.8$ & $<0.001$ \\
\hline $15+$ & 0.6 & $0.5,1.1$ & 0.113 & 0.8 & $0.4,1.4$ & 0.421 \\
\hline \multicolumn{7}{|l|}{ Beer (units per two weeks) } \\
\hline None (ref) & 1 & & & 1 & & \\
\hline $1-14$ & 0.6 & $0.6,0.7$ & $<0.001$ & 0.8 & $0.7,0.9$ & 0.001 \\
\hline $15+$ & 1.1 & $0.8,1.5$ & 0.604 & 1.1 & $0.8,1.5$ & 0.642 \\
\hline \multicolumn{7}{|l|}{ Liquor (units per two weeks) } \\
\hline None (ref) & 1 & & & 1 & & \\
\hline $1-14$ & 0.8 & $0.7,0.9$ & $<0.001$ & 1.0 & $0.9,1.2$ & 0.916 \\
\hline $15+$ & 4.9 & $2.2,11.3$ & $<0.001$ & 3.3 & $1.4,7.9$ & $<0.001$ \\
\hline \multicolumn{7}{|c|}{ Light physical activity (hours per week) } \\
\hline None (ref) & 1 & & & 1 & & \\
\hline$<1$ & 0.8 & $0.6,1.0$ & 0.030 & 0.9 & $0.7,1.2$ & 0.576 \\
\hline $1-2$ & 0.5 & $0.4,0.6$ & $<0.001$ & 0.7 & $0.6,0.9$ & 0.008 \\
\hline $3+$ & 0.5 & $0.4,0.6$ & $<0.001$ & 0.7 & $0.6,0.9$ & 0.010 \\
\hline \multicolumn{7}{|c|}{ Strenuous physical activity (hours per week) } \\
\hline None (ref) & 1 & & & 1 & & \\
\hline$<1$ & 0.6 & $0.5,0.7$ & $<0.001$ & 0.8 & $0.7,0.9$ & $<0.001$ \\
\hline $1-2$ & 0.5 & 0.4 .0 .5 & $<0.001$ & 0.7 & $0.6,0.8$ & $<0.001$ \\
\hline $3+$ & 0.4 & $0.3,0.5$ & $<0.001$ & 0.5 & $0.4,0.7$ & $<0.001$ \\
\hline \multicolumn{7}{|l|}{ Smoking } \\
\hline Never smoker (ref) & 1 & & & 1 & & \\
\hline Former smoker & 0.9 & $0.8,1.0$ & 0.030 & 0.9 & $0.8,1.0$ & 0.052 \\
\hline Current smoker & 1.4 & $1.2,1.6$ & $<0.001$ & 1.2 & $1.1,1.4$ & $<0.001$ \\
\hline
\end{tabular}

